\title{
COMPUTATIONAL APPROACH TO IMPROVE BEARINGS BY RESIDUAL STRESSES BASED ON THEIR REQUIRED BEARING FATIGUE LIFE
}

\author{
F. PAPE ${ }^{1}$, O. MAISS ${ }^{2}$, B. DENKENA ${ }^{2} \&$ G. POLL ${ }^{1}$ \\ ${ }^{1}$ Institute for Machine Design and Tribology, Leibniz Universitaet Hannover, Germany. \\ ${ }^{2}$ Institute of Production Engineering and Machine Tools, Leibniz Universitaet Hannover, Germany.
}

\begin{abstract}
In drive systems and component technology a high reliability is very important for machines. Machine element dimensions are calculated for reliability. The properties for these elements are based on conventional manufacturing techniques. Very high stresses are applied on bearings in their operating time. To improve the endurance life, residual stresses can be induced into the subsurface zone. In contrast to a conventional grinding process, the mechanical surface modification process deep rolling is able to induce very high compressive residual stresses. A computational approach was developed to establish an appropriate residual stress depth profile matching the applied loads. Thus, the costs of manufacturing can be chosen in accordance to the required properties. The method to determine the residual stresses is based on an iterative reverse calculation of an existing bearing fatigue life model of Ioannides $e t$ al. The model originates from the approach of Lundberg and Palmgren (1947) including a stress fatigue limit $\tau_{\mathrm{u}}$. For the term $\tau_{\mathrm{i}}$, the fatigue criterion of Dang-Van is applied. The equation accounts for the maximum orthogonal shear stress and the local hydrostatic pressure $p_{\text {hyd }}$, corrected for residual and hoop stress. The inputs into the computational model are the stresses on the surface, which are simulated based on the load and geometry of the contact between roller and bearing surface. As an output the required residual stress profile underneath the bearings raceway is given to achieve a bearing fatigue life as required for the given application. In order to verify the model, the bearing fatigue life was experimentally determined for a given residual stress profile by experiments.

Keywords: bearing fatigue life, inverse computational model, residual stresses.
\end{abstract}

\section{INTRODUCTION}

Roller bearings are typically made of 100Cr6 bearing steel (German standard corresponding to AISI52100). The investigated bearings of type NU206 have cylindrical rolling elements (rollers), which are held by a polyamide cage, Fig. 1 shows the bearing's components. In roller bearings, the contact between raceway and rolling elements is exposed to cyclic load due to the rotational motion. Alternating stresses are induced in varying depths beneath the surface of the contacting partners. The depth of the highest load induced stresses can be calculated according to the Hertzian contact theory including the approaches of Karas [1] and Föppl [2]. The normal loads onto the surface cause changes of the microstructure and may trigger crack formation beneath the surface of the raceways in the depth of highest load induced stresses.

According to Voskamp, bearing fatigue life for roller bearings can be separated into three phases [3]:

- The first phase, the so-called shakedown-phase. Within the first 1000 revolutions plastic micro deformation occurs on the raceway. These deformations lead to work-hardening of the material and a resulting decrease of the retained austenite in the martensitic matrix and a moderate change in compressive residual stresses. The influence depends on the level of the load.

- The second phase, the steady state phase, features no plastic deformations and no changes of the microstructure. The duration of the stationary phase depends on the applied stresses. 


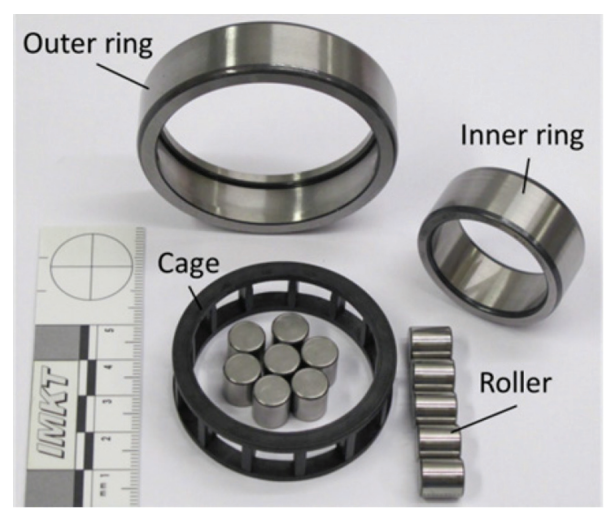

Figure 1: Components of the roller bearing.

For loads above the so-called 'Shakedown Limit' the third phase starts immediately, whereas for very low loads the bearing remains in the second phase forever and no failure due to fatigue takes place.

- The third phase, the instability phase. The inner boundary layers, conditioned in the shakedown phase, lose the ability to carry the load elastically. A local change of the microstructure takes place. Due to the phase transformation and the complex residual stress state, the material is modified. The microplastic deformations transform into macroplastic deformations. With persistent cyclic load on the inner boundary layer, cracks grow to the surface and finally pittings occur on the raceway. The depth of these pittings is equal to the depth of the highest load induced stresses. In practical applications, this failure type (Fig. 2) on the surface is one of the main failure modes of bearings (under ideal lubrication conditions and avoidance of lubricant contamination).

To increase the duration of the steady state phase, residual stresses can be induced to the inner boundary zone in the depth of the highest load induced stresses. Thus, the shakedown phase can be forestalled. To achieve pre-induced residual stresses, bearing surfaces can be reinforced with a short period of overload in the shakedown-phase, as well as in the manufacturing process. To show this, Hacke subjected NU206 bearings to a two stage test [4]. In a first step, the tests were run at a higher load for 1.5 million revolutions. The test was then continued at normal load. The tests were performed under full film lubrication with a specific film thickness of $\lambda \geq 2$. It could be shown that the bearing fatigue life increased drastically. The manufacturing process can be used to induce residual stresses not only to the near

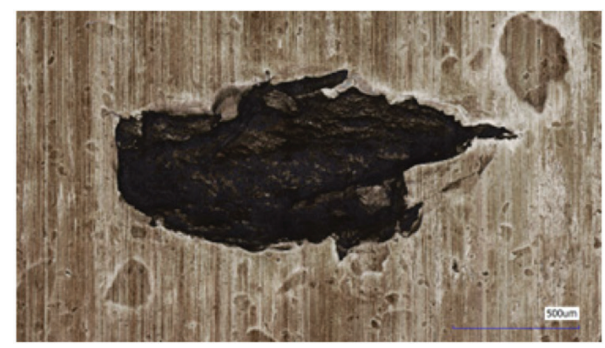

Figure 2: Damaged surface of a bearing inner ring due to fatigue. 
surface zone but to the subsurface region, too. The mechanical surface modification process deep rolling is one effective possibility to induce the compressive residual stresses. Within the process, a hard ball is pressed on a surface of a rotating part. A hydraulic pressure of up to $\mathrm{p}_{\mathrm{w}}=600$ bar can be used for the process. Neubauer et al. investigated the influence of manufacturing processes and induced residual stresses on bearing fatigue life. A computational model was set up and compared to bearing fatigue life tests [5, 6]. For the application of bearings, it is of interest to define a desired bearing fatigue life and calculate the demanded surface properties. Thus, the manufacturing process can be selected to fulfil these specifications. The aim of this paper is to introduce an inverse computational model for this application. Therefore, the calculation of bearings fatigue life will be described shortly. As a second step, the inverse computational model will be presented. From the results of the calculation, a manufacturing process will be chosen to manufacture roller bearing inner rings. At the end, the resulting bearings fatigue life will be determined experimentally.

\section{CALCULATION OF BEARING FATIGUE LIFE}

The influence of the residual stresses on the bearing fatigue life can be understood by taking a deeper look on the computational approaches. Roller bearings are highly stressed due to the cyclic contact load. To calculate the bearing fatigue life, the theoretical approaches are based on the weakest link concept by Weibull [7]. Weibull developed the following equation:

$$
\log \left(\frac{1}{S}\right)=-\int_{V} n(\sigma) d V
$$

$S: \quad$ Probability of survival

$n(\sigma)$ : Material dependent scale parameter

$V: \quad$ Damage risk volume $\left[\mathrm{mm}^{3}\right]$

For homogeneous materials the following correlation has to be chosen [7]:

$$
n(\sigma)=\left(\frac{\sigma-\sigma_{u}}{\sigma_{o}}\right)^{m},
$$

with $\sigma_{\mathrm{u}}, \sigma_{\mathrm{o}}$ and $\mathrm{m}$ as experimentally detected constants, $\sigma$ is the applied stress.

Lundberg and Palmgren developed a model for the calculation of bearing fatigue life, based on Weibull [8]. They expected a failure underneath the bearings surface for high orthogonal stresses and for imperfections of the material. In contrast to Weibull, it is expected that cracks due to fatigue occur on a weak point below the surface, e.g. an inclusion. Such cracks may extend further to the surface and finally lead to pittings. The probability of survival can be calculated as a function of the number of revolutions, the maximal orthogonal stresses, the stressed volume and the depth of the highest load induced stress.

$$
\ln \left(\frac{1}{S}\right) \propto \frac{\tau_{o}^{c} \cdot N^{e} \cdot V}{z_{o}^{h}}
$$

$N$ : Number of load cycles

$\tau_{o}: \quad$ Maximal orthogonal shear stress [MPa]

$z_{o}$ : Depth of the max. orthogonal shear stress [mm]

$c$ : $\quad$ Exponent for stress criterion

$h$ : Factor in the bearing life equation

$e$ : Exponent in the bearing life equation (standardized Weibull slope) 
In the 1980s Ioannides and Harris introduced an advanced model for the calculation of bearing fatigue life based on Lundberg and Palmgren [9]. The key point for the model is a statistical connection between the probability of surviving and a stress dependent fatigue criterion $\sigma_{\mathrm{i}}$ or $\tau_{\mathrm{i}}$, respectively, for a volume element of the bearings surface. The probability of surviving for a volume element of a bearing is described by the following equation:

$$
\ln \frac{1}{\Delta S_{i}}=A_{i} \cdot H\left(\sigma_{i}-\sigma_{u}\right) \cdot\left(\sigma_{i}-\sigma_{u}\right)^{c} \cdot \Delta V_{i} .
$$

$\mathrm{A}_{\mathrm{i}}$ is an independent random variable and $\mathrm{H}(\mathrm{x})$ a heaviside function with

$$
H(x)=\left\{\begin{array}{l}
1 \text { for } x \geq 0 \\
0 \text { for } x \leq 0
\end{array} .\right.
$$

The resulting stress field is used as input for the fatigue life model of Ioannides et al. [10].

The equation is:

$$
\ln \left(\frac{1}{\mathrm{~S}}\right) \approx \mathrm{N}^{\mathrm{e}} \int_{\mathrm{V}} \frac{\left(\tau_{\mathrm{i}}-\tau_{\mathrm{u}}\right)^{\mathrm{c}}}{\mathrm{z}^{\mathrm{s}}} \mathrm{dV}
$$

$\tau_{\mathrm{i}}: \quad$ Fatigue stress criterion

$\tau_{\mathrm{u}}: \quad$ Shear stress fatigue limit $(\mathrm{Pa})$

z': $\quad$ Stress weighted depth (depth from the surface) (m)

h: $\quad$ Factor in the bearing life equation

In order to account for the depth of the maximum shear stress the weighted depth $z^{\prime}$ is introduced:

$$
z_{i}^{\prime}=\frac{\int_{0}^{z_{\max }}\left(\sigma_{i}-\sigma_{u}\right) \cdot z_{i} d z}{\int_{0}^{z_{\max }}\left(\sigma_{i}-\sigma_{u}\right) d z}
$$

The model of Ioannides et al. [10] includes a stress fatigue limit $\tau_{\mathrm{u}}$ and a fatigue stress criterion. For the term $\tau_{\mathrm{i}}$ as fatigue stress criterion the criterion of Dang-Van et al. [11] is selected:

$$
\tau_{i}=\tau_{\text {Omax }}-k_{\text {hyd }} \cdot p^{\prime}{ }_{\text {hyd }}
$$

$\tau_{\text {Omax }}:$ Max. shear stress $(\mathrm{Pa})$

$k_{\text {hyd }}$ Weighting factor for hydrostatic stresses

$p_{\text {hyd }}^{\prime}$ : Hydrostatic stress including compressive stresses

$$
p_{\text {hyd }}^{\prime}=p_{\text {hyd }}-\left[\frac{\left(\sigma_{R x}+\sigma_{R y}+\sigma_{R z}\right)}{3}+\frac{\sigma_{\text {hoop }}}{3}\right] .
$$

The Dang-Van criterion includes the maximum orthogonal shear stress and the local hydrostatic pressure, $\mathrm{p}_{\text {hyd }}$, corrected for residual and hoop stress. With increased compressive residual stresses the hydrostatic pressure is increased, thus the critical fatigue stress is reduced. The critical fatigue stress is highest in the zone of the highest load induced stresses beneath the surface. Concludingly, by applying residual stresses in this depth, the computational approach predicts that the bearing fatigue life is influenced positively. 
2.1 Computational method to determine the influence of intrinsic stresses on bearing fatigue life

In order to assess the influence of the magnitude and depth of residual stresses on bearing fatigue life, Neubauer previously developed a computational method [5, 12]. A finite element model of a bearing inner ring was set up to compute the resulting three-dimensional stress field from the superposition of load stresses and residual stresses. Figure 3 depicts the flow chart of the computational model. The input variables are the external load and the residual stress depth profile. The external load is transformed into a Hertzian pressure distribution. The residual stress depth profiles are defined as initial stresses in the model. One result of the finite element (FE) model are the orthogonal shear stresses beneath the surface. The stresses are required for the forward calculation model based on Ioannides et al. [10], which is computed in MathWorks ${ }^{\circledR}$ Matlab. The method allows determining the resulting bearing fatigue life based on the initial residual stress state of the bearings surface.

\section{INVERSE CALCULATION OF DESIRED RESIDUAL STRESSES FOR GIVEN BEARING FATIGUE LIFE TIME}

The inverse model is based on an iterative reverse calculation of the bearing fatigue life model of Ioannides et al. [10]. It is set up to determine the required residual stress state for reaching a specified bearing fatigue life. The inputs into the computational model are the stresses on the surface, which are simulated based on the load and geometry of the contact between roller and bearing surface. The load and basic rating life $\mathrm{L}_{10}$ (bearing life that $90 \%$ of a sufficiently large group of identical bearings reach or exceed before fatigue appears). Output is the required residual stress state in the bearing surface to achieve a bearing fatigue life as required for a given application. The flow chart of the inverse model is shown in Fig. 4.

The calculation is performed in Matlab, the flow chart is shown in Fig. 5. For the model, the Dang-Van criterion as well as the approach of Ioannides and Harris are used. Due to the

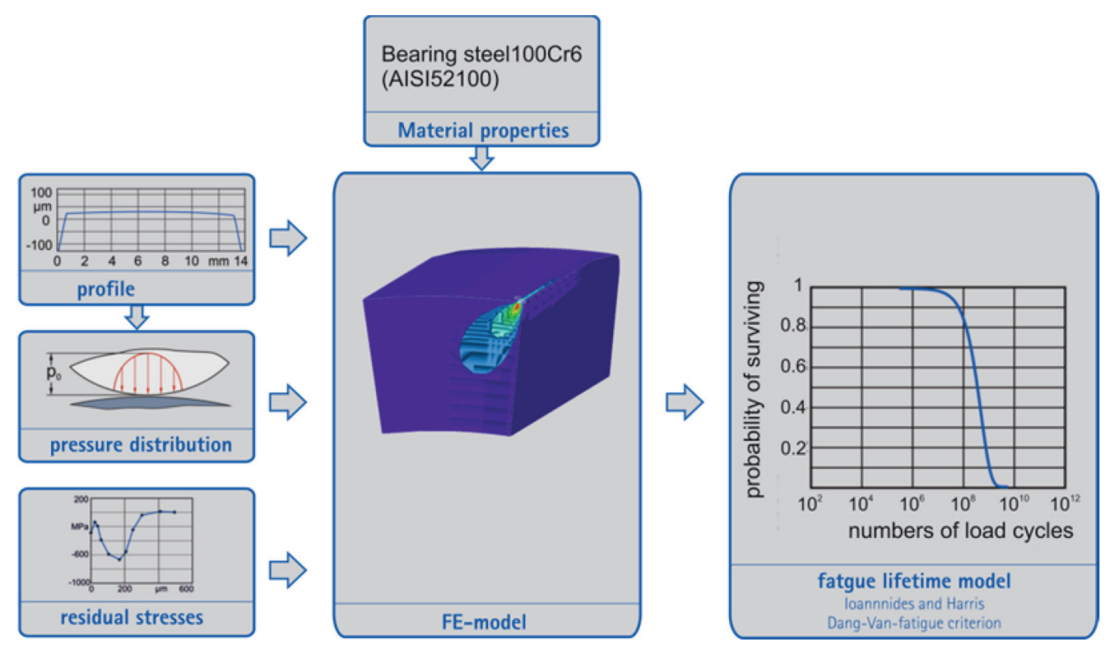

Figure 3: Flow chart of the forward computational approach based on Neubauer [5] to calculate the influence of residual stresses on bearing fatigue life. 


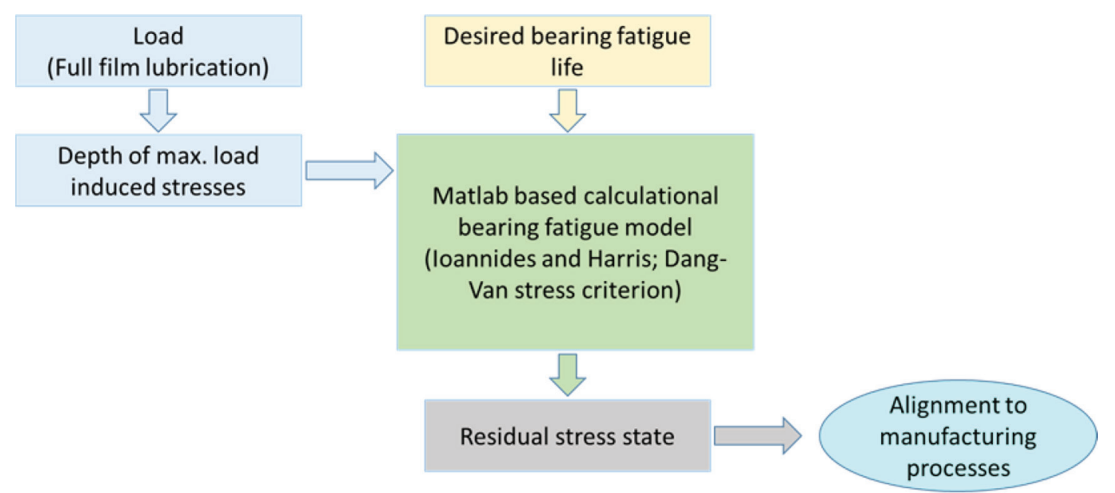

Figure 4: Flow chart for the inverse computational model to calculate the residual stress state desired to reach pre-defined bearing fatigue life.

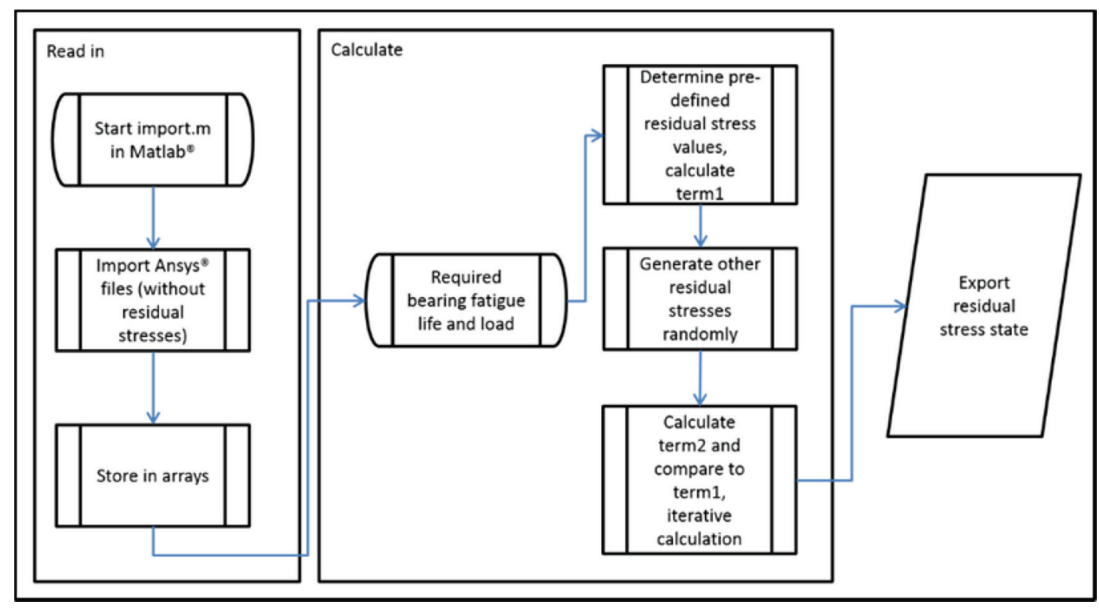

Figure 5: Flow chart of the Matlab program to define the residual stress state.

approach including a heaviside function the intrinsic stresses cannot be calculated directly, see eqn (9).

In a first step of the calculation, the intrinsic stresses are generated for one point randomly based on previous results of the forward calculation method by Neubauer. The early calculations proved a dependency of the residual stress formed in higher depth and achievable bearing fatigue life. Distribution functions of the residual stress depth profiles originating from the bearings surface are calculated based on the Matlab curve fitting tool.

To calculate the Dang-Van criterion the input based on the shear stress, hydrostatic pressure and residual stresses are used. As the approach of Ioannides and Harris considers that only stresses above the stress fatigue limit result in fatigue, the Dang-Van criterion is used for calculations. The model of Ioannides and Harris can be transformed by introducing two terms.

$$
\ln \left(\frac{1}{S}\right)=N^{e} \sum_{i=1}^{n} A_{i} H\left(\sigma_{i}-\sigma_{u}\right)\left(\sigma_{i}-\sigma_{u}\right)^{c}\left[\frac{\sum_{i=0}^{n-1}\left(\sigma_{i}-\sigma_{u}\right)}{\sum_{i=0}^{n-1}\left(\sigma_{i}-\sigma_{u}\right) \cdot z_{i}}\right]^{h} \Delta V_{i},
$$




$$
\begin{gathered}
\operatorname{term} 1=\frac{\ln \left(\frac{1}{S}\right)}{\tilde{A} \cdot N^{e}}, \\
\operatorname{term} 2=\sum_{i=1}^{n} \frac{\left(\sigma_{i}-\sigma_{u}\right)^{c}}{z_{i}^{h}} \Delta V_{i}
\end{gathered}
$$

(12) for $\mathrm{H}=1$.

For the generation of the residual stresses both equations are calculated and balanced. The iterations have to be continued, until both terms converge. After finishing the iteration the resulting residual stress state is calculated and plotted. Figure 6 shows calculated residual stress states for pre-defined bearing fatigue life under a contact pressure of 3,000 MPa. The graphs illustrate the trend that for increasing bearing fatigue life the residual stresses have to be increased and induced into higher depths. For increased bearing rating life the value and depth of the compressive residual stresses have to be adjusted. Figure 7 depicts the calculated residual stress state for a contact pressure of 2,300 $\mathrm{MPa}$ and a pre-defined bearing rating life $\mathrm{L}_{10}=1,750 \mathrm{~h}$. Due to the lower contact pressure the depth of highest load induced stress is in

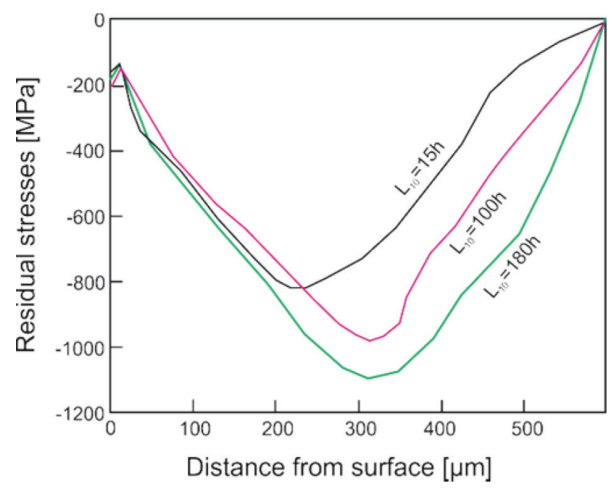

Figure 6: Calculated optimized residual stress state for pre-defined bearing fatigue life (contact pressure of $3000 \mathrm{MPa}$ ).

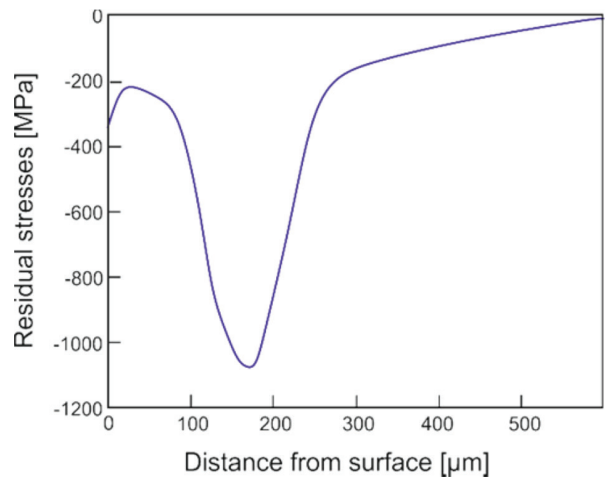

Figure 7: Pre-defined optimized residual stress state for a contact pressure of $2300 \mathrm{MPa}$; $\mathrm{L}_{10}=1750 \mathrm{~h}$. 
lower depths compared to the graphs in Fig. 6. The compressive residual stresses should be highest in a depth of approx. $150 \mu \mathrm{m}$.

\section{MACHINING OF ROLLER BEARINGS WITH SPECIFIC RESIDUAL STRESS DESIGN BY HARD TURNING AND DEEP ROLLING}

To proof the presented model, machining tests were conducted. For the tests roller bearing inner rings type NU206 were machined by hard turning and deep rolling on a high precision lathe Hembrug Microturn 100. Within the experiments, the influence of process parameters on the residual stress depth profile was analysed. The residual stresses were measured with an X-ray diffractometer Seiffert XRD $3000 \mathrm{P}$ using $\mathrm{CrK} a$ radiation. The experimental procedure and results are described in detail by Denkena et al. [13, 14].

The deep rolling process influences the residual stress state significantly. Figure 8 summarizes the experimental results. An increasing rolling pressure $\mathrm{p}_{\mathrm{w}}$ leads to higher amplitude and larger depth of the compressive stresses. The size of the rolling tool, $\mathrm{d}_{\mathrm{k}}$, affects the resulting depth of the residual stress profile. The effect of the overlap factor $u$ can be compared with the effect of the shake down phase in bearings. An increased overlap factor results in an increased number of rolling processes, which leads to higher compressive residual stresses. From the results, a regression model is generated to calculate the resulting subsurface properties by the processes hard turning and deep rolling. To achieve the residual stress state depicted in Fig. 7 the process parameters summarized in Table 1 were chosen. The achieved residual stress state is shown in Fig. 9.
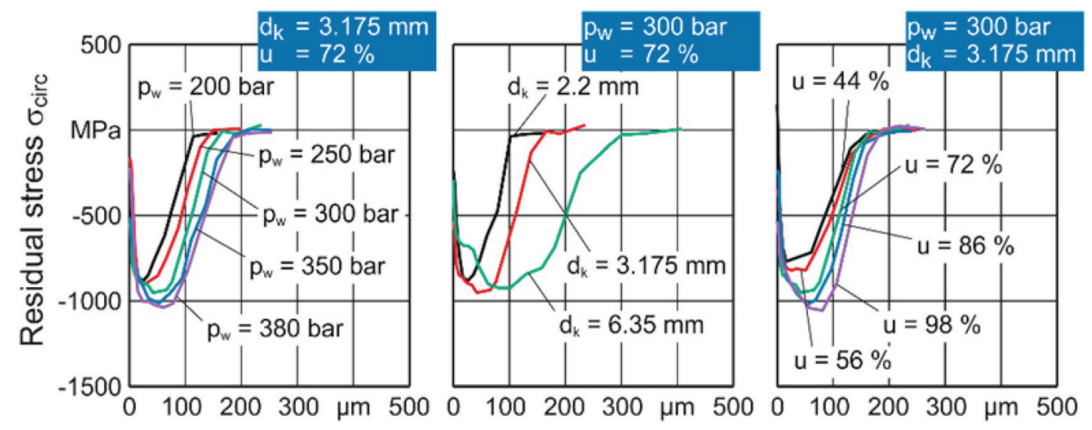

Distance from the surface $z$

\begin{tabular}{|c|c|c|}
\hline $\begin{array}{l}\text { Process: Deep rolling } \\
\text { Rolling pressure: } \\
\text { Ball diameter: }\end{array}$ & $\begin{aligned} \mathrm{p}_{\mathrm{w}}= & 200-380 \text { bar } \\
\mathrm{d}_{\mathrm{k}}= & 2.2 ; 3.175 \\
& 6.35 \mathrm{~mm}\end{aligned}$ & $\begin{array}{l}\text { Tool: } \quad \text { Ecoroll HGx } \\
\text { Ball material: Ceramic } \\
\text { Part material: AISI } 52100 \text { (62 HRC) }\end{array}$ \\
\hline $\begin{array}{l}\text { Rolling velocity: } \\
\text { Overlap factor: }\end{array}$ & $\begin{array}{l}\mathrm{v}_{\mathrm{w}}=150 \mathrm{~m} / \mathrm{min} \\
\mathrm{u}=44-98 \%\end{array}$ & Hembrug Slantbed 100 \\
\hline
\end{tabular}

Figure 8: Effect of machining parameters in hard turning and deep rolling on residual stress state.

Table 1: Chosen process parameters to induce residual stress depth profile.

\begin{tabular}{llllll}
\hline Hard turning & \multicolumn{5}{c}{ Deep rolling } \\
\hline cutting speed $\mathrm{v}_{\mathrm{c}}$ & $\mathrm{m} / \mathrm{min}$ & 200 & rolling pressure $\mathrm{p}_{\mathrm{w}}$ & bar & 300 \\
feed $\mathrm{f}$ & $\mathrm{mm}$ & 0.05 & rolling speed $\mathrm{v}_{\mathrm{w}}$ & $\mathrm{m} / \mathrm{min}$ & 150 \\
depth of cut $\mathrm{a}_{\mathrm{p}}$ & $\mathrm{mm}$ & 0.1 & ball diameter $\mathrm{d}_{\mathrm{k}}$ & $\mathrm{mm}$ & 6.35 \\
cutting edge radius $\mathrm{r}_{\beta}$ & $\mu \mathrm{m}$ & 25 & overlap factor $\mathrm{u}$ & $\%$ & 98 \\
\hline
\end{tabular}




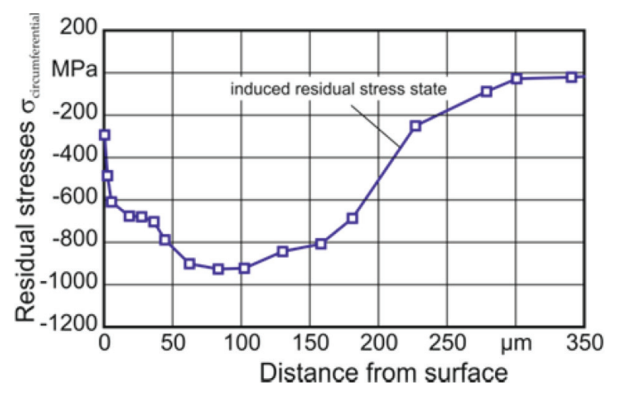

Figure 9: Pre-induced residual stress state.

\section{EXPERIMENTAL EVALUATION OF THE INFLUENCE OF RESIDUAL STRESSES ON BEARING FATIGUE LIFE}

To verify that with the chosen residual stress state resulting from the computational model the requested bearing fatigue life is achieved, experiments were conducted. Bearings without and with beneficial residual stress states were taken for the tests. Standard NU206 bearing inner rings, featuring no significant residual stresses in higher depth, were compared to bearings with a beneficial residual stress state induced by the manufacturing process. By increasing the pressure for the deep rolling process, the magnitude of the residual stresses can be enhanced whereas by increasing the diameter of the rolling tool the stress field is extended into greater depths. Modified bearing inner rings and standard parts for the rollers and outer rings were subjected to the tests.

The evaluation of the experimental bearing endurance time was performed at six identical 4-bearing endurance test benches. Each of the test rigs allows for running four equal roller bearings of type NU206 C3 at the same time. Thus, higher statistic coverage can be achieved faster in the experiments. All bearings are exposed to the same radial load in the test rig. The applied load is measured with a load cell during testing. The tests were performed under full film lubrication with a specific film thickness of $\lambda \geq 2$. The bearings are supplied with tempered oil (at $60^{\circ} \mathrm{C}$ ). A synthetic oil was chosen with a kinematic viscosity of $\eta_{40}=68 \mathrm{~mm}^{2} / \mathrm{s}$. Bearing failures due to pitting are detected with a condition monitoring system. The radial load was chosen with $\mathrm{C} / \mathrm{P}=4$ equal to a maximum Hertzian contact pressure of $\mathrm{p}_{\max }=2,300 \mathrm{MPa}$ in the bearing. The rotational speed was $4,050 \mathrm{~min}^{-1}$. The tests were performed according to the sudden death test principle. When the fatigue life of one of the bearings is reached and a pitting has formed, the other three bearings are suspended. Figure 10 shows a schematic of the test rig.

After failure, the bearings were disassembled and analysed. For the statistical evaluation, the maximum-likelihood method is applied. Thus, the bearings without failure are accounted for as "suspended".

The standard honed bearings reached an $\mathrm{L}_{10}$ of $274 \mathrm{~h}$, and an $\mathrm{L}_{50}$ of about 7,000 h. In comparison, for bearings with pre-induced residual stresses on the inner rings, an $\mathrm{L}_{10}$ of 1,924 $\mathrm{h}$ and an $\mathrm{L}_{50}$ of $8,446 \mathrm{~h}$ could be observed. The experimentally validated bearing life is close to the calculated $\mathrm{L}_{10}$ of $1,750 \mathrm{~h}$ (Fig. 7). For these bearings, the residual stress state remained nearly constant over the test duration. After an ultra-long running time of 378 Mio revolutions, the residual stresses start to decrease in the zone of the highest load induced stresses. Thus, in accordance with Voskamp [3], the breakdown phase is forestalled and the duration of the steady state phase could be increased. 


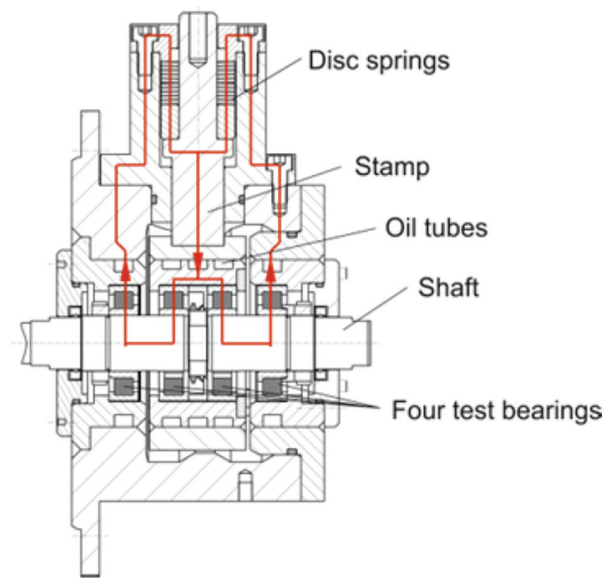

Figure 10: Schematic of the test rig to evaluate the computational approach.

\section{CONCLUSION}

Applying residual stresses on bearing surfaces offers the possibility to increase the bearing fatigue life drastically. To equip these bearings with the desired surface properties, a calculation procedure was established. The heaviside function of the bearing fatigue life model by Ioannides and Harris requires an iterative approach to determine the optimum residual stresses based on the Dang-Van criterion. The calculated residual stress state was compared to measurements showing a good agreement. The inverse computational model allows for choosing the proper manufacturing processes particularly deep rolling processes delivering the desired stress state. Thus, the manufacturing effort can be adjusted according to the desired bearing properties. The bearings can be equipped with improved properties and machines designed regarding improved resource efficiency. Especially, for applications with complicated and expensive replacement of failed bearings (such as windmills and aerospace), such approaches are valuable.

\section{ACKNOWLEDGMENT}

The authors thank the DFG (German Research Foundation) for supporting this project in the context of the research program 'Resource efficient Machine Elements (SPP1551)'.

\section{REFERENCES}

[1] Karas, F., Werkstoffanstrengung beim druck achsenparalleler Walzen nach den gebräuchlichen Festigkeitshypothesen. Forschung auf dem Gebiet des Ingenieurwesens, 11(6), pp. 334-339, 1940. https://doi.org/10.1007/BF02583244

[2] Föppl, L., Der Spannungszustand und die Anstrengung des Werkstoffes bei der Berührung zweier Körper. Forschung auf dem Gebiet des Ingenieurwesens, 7(5), p. 209, 1936. https://doi.org/10.1007/BF02585815

[3] Voskamp, A., Microstructural changes during rolling contact fatigue - metal fatigue in the subsurface region of deep groove ball bearing inner rings, Technische Universität Delft, Thesis, 1996. 
[4] Hacke, B., Radnai, B. \& Hinkelmann, K., Berücksichtigung von Betriebszuständen, Sonderereignissen und Überlasten bei der Berechnung der Wälzlager-Lebensdauer in Windenergieanlagen und Großgetrieben. Abschlussbericht FVA Forschungsheft Nr. 967, AiF-Nr. 15227 N, 2011.

[5] Neubauer, T., Betriebs- und Lebensdauerverhalten hartgedrehter und festgewalzter Zylinderrollenlager, Leibniz Universität Hannover, IMKT. Doctoral Thesis, 2015.

[6] Denkena, B., Poll, G., Maiß, O., Pape, F. \& Neubauer, T., Enhanced boundary zone rolling contact fatigue strength through hybrid machining by hard turn-rolling. Bearing World Journal, Volume 1, Proceedings of the 1st Bearing World Conference 12-13 April 2016, Hanover/Germany, ISBN 978-3-8163-0705-1, pp. 87-102, 2016.

[7] Weibull, W., A Statistical Theory of the Strength of Materials. Generalstabens litografiska anstalts förlag, 1939. (Ingeniörsvetenskapsakademiens handlingar)

[8] Lundberg, G. \& Palmgren, A., Dynamic Capacity of Rolling Bearings. Generalstabens Litografiska Anstalts Förl, 1947 (Acta polytechnica. Mechanical engineering series).

[9] Ioannides, E. \& Harris, T.A., A new fatigue life model for rolling bearings. Journal of Tribology, 107(3), pp. 367-377, 1985. https://doi.org/10.1115/1.3261081

[10] Ioannides, E., Bergling, G. \& Gabelli, A., An analytical formulation for the life of rolling bearings. In: Acta Polytechnica Scandinavica, Mechanical Engineering Series No. 137, 1999.

[11] Dang Van, K., Griveau, B. \& Message, O., On a new mulitiaxial fatigue criterion: theory and application. In: M.W. Brown \& K.J. Miller (eds), Mechanical Engineering Publications, London, pp. 479-496, 1989.

[12] Pape, F., Neubauer, T., Maiss, O., Denkena, B. \& Poll, G., Influence of manufacturing processes and related residual stresses on bearing fatigue life, TFC - Tribology Frontiers Conference, STLE, 14. November 2016.

[13] Denkena, B. Grove, T. \& Maiß, O., Influence of the cutting edge radius on surface integrity in hard turning of roller bearing inner rings. Production Engineering, 9(3), pp. 299-305, 2015.

https://doi.org/10.1007/s11740-015-0615-X

[14] Denkena, B., Grove, T. \& Maiß, O., Influence of hard turned roller bearings surface on surface integrity after deep rolling. Proceedia CIRP, 45, pp. 359-362, 2016.

https://doi.org/10.1016/j.procir.2016.02.047 